\title{
ТРАНСФОРМАЦИОННАЯ ИННОВАЦИОННАЯ ПОЛИТИКА: МИРОВАЯ ПРАКТИКА И ВЫЗОВЫ ДЛЯ БЕЛАРУСИ
}

\author{
Н.И. Богдан
}

Рассмотрены теоретические аспекты формирования новой модели инновационной политики трансформационной, особенностью которой является согласование социальных и экологических проблем с инновационными целями. На основе анализа зарубежной практики выявлены две основные тенденции современной трансформационной инновационной политики: формирование инновационных проектов, ориентированных на миссии, и активизация взаимодействия власти и бизнеса в условиях цифровой трансформации. В этом контексте предложены направления совершенствования инновационной политики Беларуси.

Ключевые слова: инновационная политика, инновационные проекты, трансформация, миссия, цифровизация.

JEL-классификация: O30, O38.

DOI: $10.46782 / 1818-4510-2020-3-4-20$

Материал поступил 24.06.2020 2.

Инновационная политика Беларуси формируется на основе Закона Республики Беларусь от 10 июля 2012 г. «О государственной инновационной политике и инновационной деятельности в Республике Беларусь», Государственных программ инновационного развития (ГПИР), Программ социально-экономического развития Республики Беларусь на пятилетие. Стратегические основы движения задаются Национальной стратегией устойчивого развития страны до 2030 года (НСУР-2030). Если задачи Государственной программы инновационного развития 2011-2015 гг. в основном были нацелены на проекты модернизации экономики на основе новых технических решений и освоения новых видов продукции, то задачи ГПИР 2016-2020 связаны с развитием высокотехнологичного сектора экономики и совершенствованием традиционных отраслей экономики на новых технологиях.

Рассматривая итоги развития экономики в прошедшее десятилетие (2009-2019 гг.), экономисты отмечают, что эффективность инвестиций в технологические решения по модернизации экономики была низкой, называя этот процесс «инвестиционным фундаментализмом» (Крук, 2020). Проекты в отраслях деревообработки, цементной, целлюлозно-бумажной промышленности не продуцировали прибыли, а требовали дополнительной бюджетной поддержки. Инновации, основанные на модернизации, не привели к экономическому росту. За период 20152019 гг. ВВП в Беларуси вырос лишь на 0,7\% (Там же. С. 16). Возросла доля низкорентабельных и убыточных предприятий. В 2019 г. 14,7\% всех действующих компаний работали с убытками, в I квартале 2020 г. их доля увеличилась до 24\%. Задолженность по просроченным кредитам и займам государственных предприятий выросла практически в 10 раз с 0,9\% ВВП в 2012 г. до почти 2\% в 2019 г. (Гайдук, 2020. С. 26).

Результаты выполнения заданий ГПИР 2016-2020 гг. по росту сектора высоких технологий выглядят лучше, доля валовой добавленной стоимости сектора информационно-коммуникационных техно-

* Богдан Нина Ивановна (bohdannina@gmail.com), доктор экономических наук, профессор, Белорусский государственный экономический университет (г. Минск, Беларусь). 
логий (ИКТ) увеличилась в ВВП страны за 2015-2019 гг. с 3,5 до 6,2\%, экспорт ИКТ услуг за десятилетие возрос в 5 раз и составляет $21 \%$ всего экспорта услуг ${ }^{1}$. Вместе с тем инновационная активность данного сектора экономики невысока. Удельный вес инновационно активных организаций сектора ИКТ в общем числе организаций сектора ИКТ на 2018 г. составляет лишь 12,3\%. При этом следует отметить ежегодное снижение данного показателя. В 2017 и 2016 гг. он составлял 15,7 и 16,4\% соответственно. Экспорт продукции высоких технологий в экспорте промышленной продукции сохраняется на уровне $3-4 \%$, что ниже, чем в России (11\%), Армении $(7,1 \%)$, (Литве $12,1 \%)^{2}$, и показывает слабое воздействие ИКТ-сектора на развитие промышленности страны.

Задание по росту наукоемкости ВВП (затраты на научные исследования и разработки в процентах к ВВП) в ГПИР 20112015 не выполнены, незначительный рост наукоемкости за последние годы (с 0,5 до 0,61\% ВВП в 2018 г.) не позволил реализовать задание НСУР 2020 (2,5\% ВВП), в ГПИР 2016-2020 данный показатель не предусмотрен как обязательный, что расходится с мировой тенденцией роста затрат на науку как условие формирования экономики знаний и реализации целей устойчивого развития.

Целью статьи является анализ мировой практики инновационной политики, современных тенденций развития и определение направлений ее совершенствования для экономического роста и увеличения благосостояния граждан страны. Задачи исследования: выявить теоретические особенности современного этапа развития инновационной политики; рассмотреть характеристики научно-технической и инновационной политики в условиях реализации целей устойчивого развития; определить особенности проектов, ориентированных на миссии; на основе анализа международной практики установить спе-

1 Информационное общество Республики Беларусь: стат. сборник. URL: https://www.belstat.gov.by/upload/ iblock/d70/d70177df955d97e7780c924986cfe5f1.pdf

2 URL: https://knoema.ru/WBWDI2019Jan/worlddevelopment-indicators-wdi цифику инновационной политики и формы взаимодействия власти и бизнеса в условиях цифровизации; определить задачи развития инновационной деятельности для Беларуси.

\section{Изменение модели научно-технической и инновационной политики}

Концептуальные основы научно-технологической и инновационной политики определяются историческим контекстом. Можно выделить три концептуальных подхода к формированию механизмов и инструментов инновационной политики. Первая модель основана на участии государства в поддержке науки и инноваций для ликвидации провалов рынка и расширения поддержки производства новых знаний. Она сформирована в 50-х годах XX в. после Второй мировой войны. Вторая модель появилась в результате развития процессов глобализации, и ее акцент - на формировании национальных систем инноваций для роста конкурентоспособности и коммерциализации знаний. Фокусом инновационной политики в этой модели стали создание связей, кластеров и сетей, а также стимулирование обучения и предпринимательства. Третья модель связана с современными социальными и экологическими задачами, такими как реализация целей в области устойчивого развития, и определяется трансформационными изменениями во всех сферах жизни общества.

Первая модель опиралась на теории экономического роста, основные черты которых С. Кузнец идентифицировал как формирование наукоемких отраслей и устойчивое улучшение факторной производительности (Kuznets, 1973). Она была направлена на развитие массового производства и потребления. М. Абрамовиц и Р. Солоу продемонстрировали, что вклад труда и капитала далеко не объясняет рост производства, оставляя остаток, который Р. Coлоу назвал технологическими изменениями ${ }^{3}$. Научное сообщество нашло согласие в

3 Abramovitz M. 1956. Resource and output trends in the United States since 1870. American Economic Review. Vol. 46. No 2. PP. 5-23; Solow R.M. 1957. Technical change and the aggregate production function. The Review of Economics and Statistics. Vol. 39. No 339. PP. 312-320. 
отношении того, что государство может и должно играть активную роль в проведении научных исследований, предполагая, что новые научные открытия будут воплощаться в жизнь благодаря прикладным исследованиям и разработкам бизнеса. Было признано, что наука вносит существенный вклад в модернизацию промышленности, заменяя ремесленные практики и традиции на основе научного управления. Акцент на роли науки и техники привел к созданию многих инструментов политики, направленных на стимулирование НИОКР в бизнесе, создание налоговых льгот для инвестиций в науку, прямые субсидии для отдельных отраслей промышленности и др. Эта инновационная модель называлась «линейной моделью» и предполагала, что инновации основаны на научных исследованиях.

В 80-е годы ХХ в. стало очевидным, что сближение стран с более высоким и низким уровнем доходов происходит гораздо более медленными темпами, чем это можно объяснить, исходя из предположения о том, что научные и технологические знания являются глобальным общественным благом, доступным для всех в мире, что заставило ученых пересмотреть линейную модель инноваций. Во-первых, было признано, что научные и технические знания часто содержат важные неявные элементы. Знания не распространялись свободно на географические и культурные расстояния (von Hippel, 1976). Во-вторых, способность усвоения знания зависит как от способностей исследователей к их освоению, так и предшествующего опыта в связанных исследованиях и их применении (Cohen, Levinthal, 1989). В-третьих, «способности к освоению» зависят от восприимчивости к инновациям и институциональной среды, определяющей возможности предпринимательства (Лученок, 2018).

Исследователи ввели в употребление термин «национальные системы инноваций» для определения различий в конфигурациях организаций, занимающихся созданием и использованием научных и технологических знаний (Freeman, 1988; Lundvall, 1992). В исследованиях обратной связи между прикладными исследованиями, разработками и коммерциализацией обоснована «цепная модель инноваций» (Kline, Rosenberg, 1986). Было доказано, что инновации часто инициируются пользователями (user innovation) (von Hippel, 1988). Вторая модель научно-технологической и инновационной политики, таким образом, формировалась на базе цепной модели инновации и идеи национальной системы инноваций. Главной целью политики в области науки, техники и инноваций (R\&I) становится поддержание конкурентоспособности, а государства должны помочь в создании национальной системы инноваций либо для сохранения, либо для расширения конкурентных преимуществ отечественных компаний. Вместо линейного перехода - от науки к прикладным НИОКР и коммерциализации - вторая концепция признает, что знания генерируются посредством взаимодействия разнообразных субъектов в национальных, отраслевых и региональных инновационных системах. Эти взаимодействия включают в себя процесс интерактивного обучения и создание возможностей для поглощения и адаптации знаний. Часто инструменты политики включают условия финансирования, например финансирование исследований при условии участия в сети других организаций, создание кластеров. Исследования М. Маццукато в последние годы обращают внимание на важную роль финансов в национальных системах инноваций и акцентируют внимание на роли государства не только как стороны, финансирующей науку, но также и принимающей риски в разработке новых технологий (Mazzucato, 2017). Она утверждает, что государство призвано обеспечить долгосрочные финансовые ресурсы для обеспечения коммерциализации и распространения инноваций. Г. Ицковиц и Л. Лейдесдорф, используя термин «тройная спираль», стремились отобразить и проанализировать новые формы инновационного сотрудничества, возникающие между учреждениями науки, бизнеса и правительства, рассмотреть процессы управления, которые согласовывают интересы этих различных учреждений (Etzkowitz, Leydesdorff, 1997). Важным современным акцентом в политике являются «инклюзивные инновации», направленные на макси- 
мальное вовлечение в инновационные процессы различных участников. Г. Дютрен и Д. Сац подчеркивают необходимость подходов в политике на основе участия, чтобы демократизировать производство знаний (Dutrénit, Sutz, 2014).

Для решения социальных (неравенства, бедности) и экологических проблем требуется сосредоточить внимание на особенностях современных социально-технических систем, основанных на более экологичном производстве, повышении социальной справедливости, более справедливом распределении благосостояния, устойчивых моделях потребления и новых способах обеспечения экономического роста.

Эти особенности современного развития сформировали третью модель научно-технической и инновационной политики - трансформационную инновационную политику, которая предложена исследователями Сассекского университета Великобритании Й. Шото, и В.Э. Стейнмюллером (Schot, Steinmueller, 2018). Основаниями для нового подхода к политике стали требования согласовать социальные и экологические проблемы с инновационными целями. Изменение климата, увеличение неравенства, нищета и загрязнение превратились в проблемы и возможности для политики в области науки, техники и инноваций. Организация Объединенных Наций (2015г.) сформулировала 17 целей в области устойчивого развития, призывая к более экологичному производству, повышению социальной справедливости, более справедливому распределению благосостояния, устойчивым моделям потребления и новым способам обеспечения экономического роста. Политики рассчитывают, что инновации позволят решить многие проблемы современности. Предполагается, что инновационная политика может привести к «зеленому» росту, при котором правительства могут инвестировать средства в сферу чистых технологий для уменьшения загрязнения окружающей среды. Допускается также, что неравенство будет сокращено за счет новых рабочих мест, созданных благодаря росту и перераспределению доходов. Ряд ученых считают, что существующие национальные системы инноваций, научно-технологическая и инновационная политика не подходят для решения экологических и социальных проблем. Если Й. Шумпетер говорил о «созидательном разрушении», то современные исследователи считают, что инновации могут также привести к «разрушительному созиданию», принося пользу немногим за счет большинства, приводя к низкокачественным рабочим местам и создавая больше проблем, чем решают (Soete, 2013). Инновации вносят вклад в существующую ресурсоемкую, расточительную парадигму массового производства и массового потребления (Meadows, Meadows, Randers, Behrens, 1972; Steffen, Richardsonand, Rockstrцm, Cornell, 2015). Р. Каплинский считает, что инновации вносят непосредственный вклад в неравенство, потому что текущие инновационные траектории предпочитают высокотехнологичные решения, которые производят продукты массового производства, предназначенные, главным образом, для потребителей со значительной покупательной способностью (Kaplinsky, 2011).

Исследователи определяют третью концепцию научно-технологической и инновационной политики как меры, направленные на трансформационные изменения. Трансформация социотехнических систем в энергетике, мобильности, еде, воде, здравоохранении, коммуникации, магистральных системах современных обществ ${ }^{4}$ предполагает фокусирование инновационной политики на мероприятиях, поддерживающих появление новых систем мобильности, в которых, например, менее значимо владение частным автомобилем. Вместо этого - широкое использование электромобилей, специализирующихся на предоставлении услуг мобильности с использованием возможностей ИКТ. Социально-техническая системная трансформация предполагает одновременные социальные, поведенческие и технологические изменения, а также включает в себя социальные инновации, поскольку основное внимание уделяется многим социальным элементам и их связи с технологическими возможностями. УПравление трансформационными инновациями требует политического процесса, который

${ }^{4}$ OECD. 2015. Meeting 21st-century challenges with science, technology and innovation: a roadmap for policymaking. https://www.innovationpolicyplatform.org/www.innovation policyplatform.org/document/meeting-21st-century-challengesscience-technology-and-innovation-roadmap-policymaking/ index.html 
предоставляет возможность оценки и согласования разработки разнообразных путей и конкретных направлений. Поскольку трансформационные изменения связаны с изменением многих систем, они, в конечном итоге, также связаны со структурой экономики и общества. Необходимой становится координация инновационной политики с другой политикой, включая налоговую, экономическую и социальную. Конкретным выражением трансформационной инновационной политики является политика, основанная на проектах, ориентированных на миссии (или целеориентированные инновационные проекты).

\section{Инновационные проекты, ориентированные на миссии}

Трансформационная инновационная политика, опирающаяся на инновационные проекты, ориентированные на миссии (mission-oriented projects), является новым направлением инновационной политики ЕС и стран ОЭСР для стимулирования экономического роста. В результате серии исследовательских совещаний, организованных Европейской комиссией с декабря 2017 по февраль 2018 г., был подготовлен доклад «Научные исследования и инновации, ориентированные на миссии в Европейском Союзе: подход, основанный на решении проблем, для стимулирования инновационного роста» (Mission-Oriented Research \& Innovation in the European Union. A problemsolving approach to fuel innovation-led growth $)^{5}$. Такой подход к формированию нового этапа политики в сфере науки и инноващий (RE्广I) исследователи стали называть инновационной политикой, «ориентированной на миссии» (MOIP - missionoriented innovation policy), или «целеориентированной инновационной политикой»). Важным вкладом в разработку нового подхода к инновационной политике явились исследования, проведенные рядом ученых - специалистов в сфере экономики инноваций, представителем которых является профессор М. Маццукато, заведующая кафедрой экономики инноваций в Универ-

${ }^{5}$ URL: https://ec.europa.eu/jrc/communities/encom munity/european-tto-circle/article/\%E $2 \% 80 \% 98$ missionoriented-research-and-innovation-european-union-\%E2\%80\%93 ситетском колледже Лондона и специальный советник по науке и инновациям при Европейском комиссаре по научным исследованиям и инновациям. По данной проблеме в странах ОЭСР проводятся научные конференции и семинары 6 .

М. Маццукато указывает, что «способность инноваций стимулировать экономический рост давно признана. Меньше признается тот факт, что инновации определяют не только скорость роста, но и его направление. Для этого мы должны исходить из возможностей научных исследований и инноваций для достижения более широких социальных, политических и экономических целей. Только таким образом мы можем иметь инновационный рост, который также является более устойчивым и справедливым... Миссия - мощный инструмент для достижения этой цели, поскольку может предоставить средства и сосредоточить наши научные исследования, инновации и инвестиции на решении критических проблем, одновременно стимулируя рост, рабочие места» (Mazzucato, 2018. C. 4). Анализ показывает, что новый этап политики дополняет, а не заменяет старые подходы: следует принять «многослойное» видение государственной политики, где «трансформационная» инновационная политика накладывается на традиционную научно-техническую политику, с одной стороны, и на инновационную систему - с другой.

Современные миссии нацелены на решение широких задач, которые требуют долгосрочной приверженности и являются в равной степени социальными и технологическими (Foray, Mowery, Nelson, 2012). Вместе с тем социальные миссии гораздо более сложные, поскольку они сформулированы менее четко и должны совместно определяться многими заинтересованными сторонами. Современные проблемы (экологические, демографические, проблемы неравенства и др.) также требуют значительных регулятивных и поведенческих изменений как на уровне общества, так и на

${ }^{6}$ URL: https://www.researchgate.net/publication/ 336119949 Mission-Oriented Policy where do we stand Where_are_we_heading_Presentation_at_the_Vienna workshop_of_the_OECD_CSTP_project_on_Mission-oriented_ policy_Vienna_27092019; URL: https://www.oecd.org/naec/ NAEC_Mazzucato.pdf 
уровне национальных инновационных систем. Чисто научно-техническое решение не может решить такие проблемы. Даже на дисциплинарном уровне существует большая потребность в комплексном понимании социологии, политики, экономики и технологии. Анализ различий между старыми и новыми проектами, ориентированными на миссии, представлен в табл. 1.

Трансформационная политика с использованием инновационных проектов, ориентированных на миссии, имеет следующие характеристики:

- инициативы идут «сверху вниз», отвечают потребностям, которые воспринимаются обществом как неотложные (социальные вызовы), и имеют сильную политическую поддержку;

- проекты направлены не на конкретные технологии - скорее, это межотраслевые подходы вокруг той или иной темы например, проблемы климата, которые затрагивают энергетику, мобильность, переработку, технологии и многое другое;

- инициативы не ограничиваются ликвидацией технологических препятствий к реализации цели; распространение и внедрение имеют центральное значение для решения новых задач;
- инициативы разрабатываются государством в тесном сотрудничестве с заинтересованными сторонами - гражданским обществом, учеными и частным сектором;

- задачи в области управления включают этап координации с тремя ведущими сторонами: правительственный сектор; сектор научных исследований; международные организации.

Эти характеристики инновационных проектов требуют новых механизмов и инструментов политики. Миссии - это определение конкретных направлений развития, которые должны быть стратегически выбраны, поскольку проекты долговременные и общественно значимые. Выбор организаций, желающих участвовать, происходит в рамках всей экономики (в различных секторах, включая как государственную, так и частную сферу).

Миссии - это также новый способ разработки «вертикальной политики». Исследователи $^{7}$ считают, что следует избегать применения секторального подхода, поскольку возможно отрицательное воздей-

7 OECD. 2019. New mission-oriented policy initiative as systemic policies to address societal challenges: analytical framework and types of initiatives. https://pdfs.semanticscholar. org/121b/41a40768267a0b7ddb7a17d6901e73d343c2.pdf

Таблица 1

Характеристика старых и новых проектов, ориентированных на миссии

\begin{tabular}{|l|l|}
\hline \multicolumn{1}{|c|}{ Старые проекты } & \multicolumn{1}{|c|}{ Новые проекты } \\
\hline $\begin{array}{l}\text { Приоритет оборонной, ядерной и аэрокосмической } \\
\text { промышленности }\end{array}$ & $\begin{array}{l}\text { Приоритет экологическим технологиям } \\
\text { и социальным проектам }\end{array}$ \\
\hline $\begin{array}{l}\text { Распространение результатов за пределами круга } \\
\text { участников не имеет большого значения и активно } \\
\text { не поощряется }\end{array}$ & $\begin{array}{l}\text { Распространение результатов является главной } \\
\text { целью и активно поощряется }\end{array}$ \\
\hline $\begin{array}{l}\text { Миссия определяется с точки зрения технических } \\
\text { достижений, при этом их экономическая } \\
\text { целесообразность не важна }\end{array}$ & $\begin{array}{l}\text { Миссия определяется с точки зрения экономически } \\
\text { обоснованных технических решений конкретных } \\
\text { социальных проблем }\end{array}$ \\
\hline $\begin{array}{l}\text { Цели и направление технологического р азвития } \\
\text { заранее определяются небольшой группой } \\
\text { экспертов }\end{array}$ & $\begin{array}{l}\text { Направление технических изменений зависит от } \\
\text { широкого круга субъектов, включая правительство, } \\
\text { частные фирмы и группы потребителей }\end{array}$ \\
\hline $\begin{array}{l}\text { Централизованный контроль в рамках } \\
\text { государственной администрации }\end{array}$ & $\begin{array}{l}\text { Децентрализованный контроль с участием } \\
\text { большого числа субъектов }\end{array}$ \\
\hline $\begin{array}{l}\text { Участие ограничено небольшой группой фирм, что } \\
\text { обусловлено особым вниманием небольшому числу } \\
\text { радикальных инноваций }\end{array}$ & $\begin{array}{l}\text { Упор на разработку как радикальных, так и } \\
\text { постепенных (инкрементальных) инноваций, } \\
\text { позволяющих принимать участие большому числу } \\
\text { компаний }\end{array}$ \\
\hline $\begin{array}{l}\text { Автономные проекты, практически не } \\
\text { нуждающиеся в дополнительной политике, слабое } \\
\text { внимание согласованности/координации }\end{array}$ & $\begin{array}{l}\text { Дополнительные стратегии, имеющие жизненно } \\
\text { важное значение для успеха; пристальное внимание } \\
\text { уделяется согласованности с другими целями }\end{array}$ \\
\hline
\end{tabular}

Источник. Авторская разработка по (Mazzucato, 2018). 
ствие на промышленную стратегию косвенными мерами (например, налоговыми льготами), которые потенциально приводят к разбазариванию государственных средств. Подход, ориентированный на выполнение миссий, предусматривает решение конкретных проблем в целях стимулирования инновационной деятельности в различных секторах экономики. Миссии создают возможность осуществления стратегических инвестиций в рамках всей инновационной цепочки и создания потенциала для более значительных побочных эффектов во многих секторах, включая низкотехнологичные секторы экономики (Foray, Mowery, Nelson, 2012). В Германии проект «Energiewende» с его задачами по борьбе с изменением климата, поэтапному отказу от ядерной энергии, повышению энергетической безопасности за счет замены импортируемого ископаемого топлива возобновляемыми источниками и повышению энергоэффективности обеспечивает направление для технических изменений и роста в различных секторах посредством целевых преобразований в производстве, распределении и потреблении. Проект «Energiewende» представляет собой интересный пример использования комплексной стратегии, которая охватывает несколько секторов и технологий в экономике.

Как правило, проекты, ориентированные на миссии, управляются отдельными организациями. В качестве примера можно привести организации, деятельность которых ориентирована на выполнение миссий, они занимаются созданием новых рынков, а не существующими рынками. Примерами являются:

- NASA (National Aeronautics and Space Administration): «Развитие науки, техники, аэронавтики и исследование космического пространства в целях повышения уровня знаний, образования, инноваций, экономической жизнеспособности и рационального использования Земли» - миссия Национального управления по аэронавтике и исследованию космического пространства США;

- DARPA (Defense Advanced Research Projects Agency): «Создание прорывных технологий для национальной безопасности» - миссия Управления перспективных исследовательских проектов Министерства обороны США;

- NIH (National Institutes of Health): «Стремиться к фундаментальным знаниям о природе и поведении живых систем и применении этих знаний для улучшения здоровья, увеличения продолжительности жизни и сокращения заболеваемости» миссия Национального Агентства здравоохранения США.

Трансформационная инновационная политика предполагает, что государство игpaет ведущую роль. При традиционном подходе к политике государство, в лучшем случае, исправляет рыночные сбои. На этом основана неоклассическая экономическая теория, согласно которой конкурентные рынки принесут оптимальные результаты, если оставить их на произвол судьбы. Миссии являются примером более активного подхода к политике, чем исправление предложения. Они требуют, чтобы государственные организации несли ответственность за активное формирование и создание рынков и инновационной системы, а не только за исправление рыночных и системных сбоев, т. е. за создание богатства, а не просто за его перераспределение.

Миссии требуют установления динамичных отношений, создающих атмосферу доверия между участниками. Политика призвана создавать чувство сопричастности у различных слоев населения, частного бизнеса и академически заинтересованных сторон. Крайне важно также иметь возможность осуществлять эту политику путем координации усилий сети заинтересованных сторон с помощью государственного организационного потенциала, посредничества в установлении доверительных отношений и использования целенаправленных инструментов политики. Следует признать, что проблема доверия в политике Беларуси, и инновационной в частности, очень актуальна. Доверие играет первостепенную роль в таких важных для экономического развития процессах, как инвестиции и инновации, которым присуща неопределенность ввиду наличия проблемы риска и ряда трудностей, связанных с исполнением контрактов. Отрасли, нацеленные на инновации и внедрение передовых техно- 
логий (например, IT-сектор), должны предоставлять своим сотрудникам возможности для самостоятельного принятия решений и использования индивидуальных нестандартных подходов к выполнению поставленных задач. То есть для развития более сложных и конкурентных отраслей необходим больший уровень общественного доверия. По результатам социологического исследования «Ценности населения Беларуси», большая часть населения (51,9\%) склонна не доверять окружающим, при этом только14,5\% проявляют высокий уровень доверия (Борнукова, Годес, Щерба, 2020. C. 95).

Ключевую роль в реализации проектов, ориентированных на миссию, играет финансирование. Проекты требуют государственных инвестиций на протяжении всей инновационной цепочки, а не только фундаментальных исследований на начальном этапе. Например, с 1936 по 2016 г. совокупные расходы на исследования и разработки Национального института здравоохранения США (NIH) составили более 900 млрд долл. США (в долл. 2015 г.), а с 2004 г. $\mathrm{NIH}$ получает более 30 млрд долл. США ежегодно. В результате сегодня около $75 \%$ самых инновационных лекарств на рынке (так называемые «новые молекулярные» препараты с приоритетным рейтингом) появились благодаря финансированию NIH (Mazzucato, 2018). Кроме того, следует отметить, что за последние 50 лет доля расходов на НИОКР NIH в общих федеральных расходах США на НИОКР из года в год увеличивалась. Это говорит о том, что резкое увеличение абсолютных расходов на НИОКР NIH не может рассматриваться просто как результат увеличения финансирования НИОКР в стране. Это преднамеренный и целенаправленный выбор правительства в отношении того, куда направлять государственное финансирование НИОКР. Примерами инвестиций, «ориентированных на выполнение миссий», являются обязательства Европейского инвестиционного банка в размере 14,7 млрд евро по поддержке политики Германии в проекте «Energiewende» посредством экологизации и модернизации немецких отраслей промышленности и инфраструктуры. Евро- пейские данные показывают, что в условиях кризиса увеличивается бюджетное финансирование науки, а затем, после восстановления экономики, в финансировании науки продолжает лидировать бизнес. Так, в кризис 2008 г. бюджетные инвестиции ЕС в науку были в размере $1,2 \%$ ВПП, бизнеса - 1,1\% ВВП, в 2018 г. бюджетное финансирование науки в ЕС составило лишь 0,68\% ВВП, бизнеса $-1,36 \%{ }^{8}$. В этом контексте устойчивое сокращение государственных инвестиций в науку в Беларуси вызывает много вопросов. Формирование экономики знаний, реализация целей устойчивого развития (ЦУР) не может сопровождаться снижением бюджетных расходов на НИОКР (в 2008 г. - 0,34\% ВВП, в 2018 г. $-0,19 \%)^{9}$ и низким финансированием науки на уровне $0,5-0,6 \%$ ВВП.

Необходимо делать выбор, какие организации следует поддерживать, плоды которого создадут не только победителей, но и довольно много проигравших. Например, Министерство энергетики США предоставило гарантированные займы двум экологически чистым компаниям: Solyndra (500 млн долл. США) и Tesla Motors (465 млн долл. США). Tesla Motors оказалась более успешной, чем «Solyndra», этот факт показывает, что государство активно участвует на начальных стадиях рисковых инвестиций. Во многих секторах венчурный капитал появился лишь после десятилетий государственных инвестиций. Венчурный капитал вошел в биотехнологический сектор в конце 80-х - начале 90-х годов, тогда как капиталоемкие инвестиции с высоким уровнем риска были сделаны правительством США в 50-х и 60-х гг. (Mazzucato, 2017). Нередко частные венчурные капиталисты желают получить краткосрочную отдачу (обычно 3-5-летние циклы). Если государственные средства действуют в качестве публичных форм венчурного капитала, то есть основания утверждать, что вознаграждение должно быть пропорционально фактически принятым рискам. Если ожидается, что государственный сектор компенси-

8 URL: https://ec.europa.eu/growth/industry/policy/ innovation/scoreboards_en

9 URL: https://www.belstat.gov.by/ofitsialnayastatistika/realny-sector-ekonomiki/nauka-i-innovatsii/ 
рует нехватку частных средств венчурного капитала, направляемых на внедрение инноваций на ранних этапах, то он должен быть в состоянии извлечь выгоду из этих побед, как это делает частный венчурный капиталист.

Миссии должны формироваться с учетом задач, которые являются приоритетными с точки зрения общества. Это обеспечит их долговечность и выживание на протяжении всех политических циклов, будет способствовать успеху в реализации. Поэтому определение миссий должно быть открыто для более широкой группы заинтересованных сторон, включая движения в гражданском обществе. Хотя характер миссий требует их отбора на политическом уровне, процесс отбора должен иметь существенный элемент участия общественности. Это можно объяснить тем, что без участия граждан риск отчуждения общественности и чисто технократического подхода слишком высок. Участие научной общественности может предотвратить осуществление отбора в корыстных целях или под влиянием веяний моды. Возможности такого участия, разумеется, будут различаться в зависимости от характера миссии, однако для содействия открытому диалогу по ожидаемым результатам и практической применимости решений крайне важно обеспечить в той или иной форме подлинное участие организаций гражданского общества в конкретных проектах в рамках той или иной миссии. Кроме того, поскольку миссии носят межсекторальный и междисциплинарный характер, одним из ключевых элементов их осуществления будут социальные инновации.

Несмотря на то, что миссии являются достаточно широкими для привлечения общественности, они должны оставаться целенаправленными для привлечения экономических агентов и достижения успехов, поддающихся измерению. Определяя направление решения, миссии не уточняют, как добиться успеха. Напротив, они стимулируют разработку ряда различных решений для достижения этой цели. Миссии могут внести значительный и кон- кретный вклад в достижение целей устойчивого развития (ЦУР) или решение общественных проблем. Рис. 1 иллюстрирует переход от общих задач к конкретным проектам.

Исследователи показывают, что в ЦУР 14 «Сохранение и устойчивое использование океанов, морей и морских ресурсов в целях устойчивого развития» могут быть выделены различные миссии, например «Океан без пластика». Эта миссия могла бы стимулировать научные исследования и инновационные проекты в отношении способов удаления пластмассовых отходов из океанов или сокращения использования пластмасс; исследования воздействия микропластмасс на здоровье; поведенческие исследования; разработку инноваций для улучшения рециркуляции или стимулирования участия общественности в очистке пляжей (Mazzucato, 2017). Таким образом, требуется комплексный подход, основанный на различных решениях и широком диапазоне взаимодействий. Задачи должны решаться многочисленными субъектами на основе междисциплинарных научных работ с особым вниманием к взаимосвязи естественных, технических, социальных и гуманитарных наук, к сотрудничеству между различными отраслями, к новым формам партнерства государственного, частного секторов и общественных организаций.
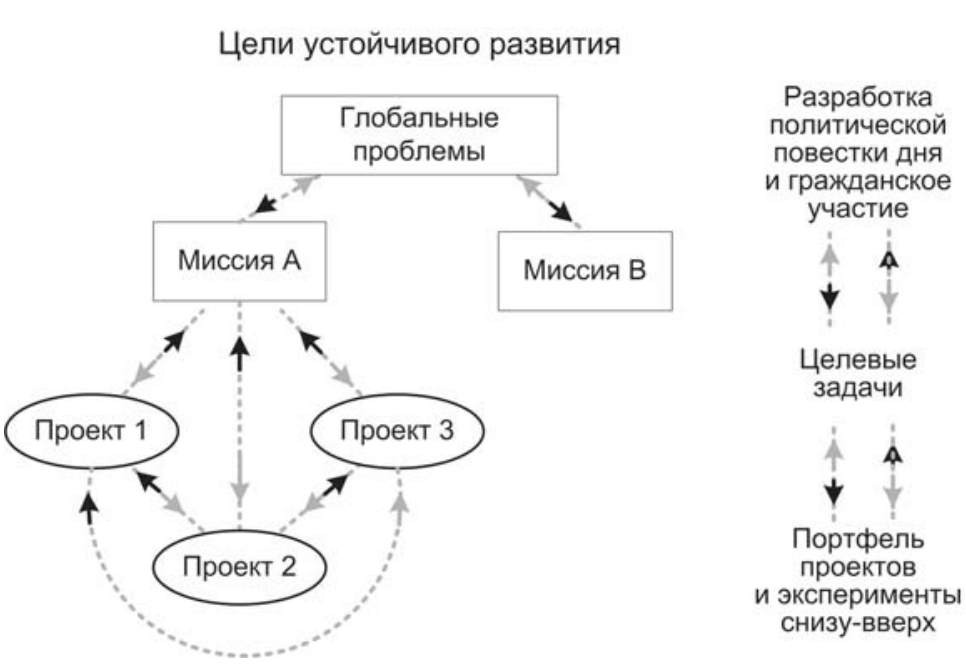

Рис. 1. От глобальных проблем к проектам, ориентированным на миссии

Источник. Авторская разработка по: (Mazzucato, 2018); URL: https://pdfs.semanticscholar.org/121b/41a40768267a0b7ddb7 a17d6901e73d343c2.pdf 
Формирование инновационной политики, основанной на миссии, планируется заложить в основу стратегии Европейского союза 2030. В отличие от предыдущих Рамочных программ ЕС, инновационная политика не должна ограничиваться использованием государственных средств для стимулирования инвестиций частных фирм в НИОКР, она призвана ориентировать / направлять инвестиции на конкретные задачи, цели, определенные политикой, в тесном взаимодействии как с государственным, так и частным сектором, а также со все более важным общественным сектором ${ }^{10}$.

\section{Взаимодействие государства и бизнеса в формировании инноващионной политики в цифровой әкономике}

Для формирования трансформационной инновационной политики в цифровую эпоху важно применять подход, основанный на «системных инновациях», который заключается в разработке инновационной политики с учетом всего комплекса стратегий и взаимосвязей различных ее областей в целях решения сложных социальных проблем. Управление преобразованиями инновационной системы требует совместного формирования общего видения будущего для использования технологических возможностей в целях достижения социально-экономических целей. Системный подход к инновационной политике в эпоху цифровых технологий может дать ряд идей для ее осмысления, направленных на поддержку инноваций для инклюзивного и устойчивого развития, и имеет следующие характеристики:

разработка сбалансированных и хорошо согласованных политических инструментов. Это необходимо для управления изменениями в системе инноваций. Важно сформировать сбалансированный и хорошо согласованный комплекс мер политики, который, по возможности, включал бы в себя как инструменты предложения, так и инструменты спроса для стимулирования инноваций и инклюзивного развития в эпоху цифровых технологий. Необходима увяз-

10 URL: https://ec.europa.eu/info/sites/info/files/ an_esir_memorandum-towards_a_mission-oriented_researchand-innovation_policy_in_the_european_union-executive_ summary.pdf ка инновационной политики с другими ее аспектами (например, научными исследованиями, вопросами образования, конкуренции, налогообложения);

вовлечение ключевых заинтересованных сторон и граждан в процессы разработки политики. Создание с этой целью механизмов может быть ключевым фактором для преодоления сопротивления изменениям, что часто является важным препятствием на пути к преобразованию системы. Такие механизмы помогают укреплять доверие, вырабатывают общее и всеобъемлющее видение преобразований и облегчают координацию действий в правильном направлении. Привлечение ключевых заинтересованных сторон (представителей промышленности и научных кругов, а также граждан, с тем чтобы лучше понять их потребности) может осуществляться через совместную работу по подготовке дорожной карты, создание многосторонних платформ или форумов для обсуждения;

содействие межсекторальному сотрудничеству в инновационной деятельности. Решение сложных социальных проблем требует вклада и совместной работы различных субъектов, в том числе отраслевых секторов и академического научного сообщества. Компаниям в цифровую эпоху часто приходится полагаться на внешние ресурсы знаний для инноваций и вступать в партнерские отношения с уже созданными и новыми фирмами как внутри секторов, так и между секторами. Важное значение может иметь такой механизм инновационной политики, как кластерная политика, а также совместные исследовательские центры;

повышение эффективности анализа политики. Сложность системных преобразований (и цифровых преобразований) требует наличия механизмов для повышения эффективности анализа политики и углубления понимания директивными органами текущих процессов, а также барьеров, посредников в конкретных секторах и технологических областях (Богдан, 2019). Эти процессы могут поддерживать стратегическое прогнозирование, которое помогает выявить импульсы для изменений, когда их сигналы являются очень слабыми, определить возможности, угрозы или уязвимости на раннем этапе, в то время как анализ 
дорожных карт позволяет собирать коллективные знания и разрабатывать общее видение среди заинтересованных сторон; адаптащия политики к различным этапам развития технологий и развития рын$\kappa a$. Определение этапа преобразований помогает разрабатывать специализированные инструменты политики. На самом раннем этапе мероприятия по определению приоритетов и прогнозированию, такие как «дорожная карта», являются важными инструментами для выработки общего видения между участниками и координации действий и интересов в правильном направлении. Далее, поддержка создания сетей между участниками имеет важное значение для расширения совместной деятельности и обмена знаниями. Совместное финансирование проектов НИОКР правительством и бизнесом на ранних этапах разработки технологий может помочь инвестициям в рисковые проекты и создать среду, в которой компании будут более уверенно инвестировать в НИОКР. На этапе роста для устранения институциональных барьеров на пути выхода на рынок могут потребоваться пересмотр, уточнение или обновление существующих нормативных положений и законодательства. Политика в области спроса, такая как государственные закупки, также может иметь решающее значение для ускорения внедрения новых технологий.

Анализ планов стратегического развития экономики Беларуси в направлении цифровизации экономики (Стратегия развития информатизации в Республике Беларусь на 2016-2022 годы; Государственная программа развития цифровой экономики и информационного общества на 2016-2020 годы; Декрет № 8 «О развитии цифровой экономики») показывает, что, несмотря на комплексность предусмотренных мер, недостаточно рассмотрены вопросы координации взаимодействия власти и бизнеса для формирования эффективной цифровой экономики, в которой ключевую роль играют современные инновации. Исследователи отмечают, что сегодня Беларусь отстает от мировых лидеров цифровой экономики на 3-4 года (Ковалев, Головенчик, 2018. С. 15). Сильный ИТ-сектор далеко не всегда является явным катализатором цифровой трансформации (Лузгина,
2020. С. 103). В этой связи целесообразно рассмотреть особенности реализации системного подхода к инновационной политике в условиях цифровизации за рубежом.

Следует отметить комплексный подход к стратегическому развитию в условиях цифровизации экономики. Во многих странах были разработаны новые политические стратегии (т. е. стратегии или планы, определяющие видение, приоритеты и общие руководящие принципы действий в области политики) в целях удовлетворения новых потребностей и решения задач, характерных для нового цифрового контекста. Цели цифровизации были включены в следующие политические стратегии: 1) национальные стратегии цифровой трансформации и стратегии развития искусственного интеллекта (ИИ); 2) стратегии в области науки, техники и инноваций; 3) стратегии промышленной политики.

Большинство стран ОЭСР имеют национальную цифровую стратегию или программу. Такие стратегии направлены на максимизацию социально-экономического потенциала цифровых технологий как средства стимулирования инноваций, роста и благополучия (табл. 2).

Анализ показывает, что национальные стратегии в области цифровых технологий традиционно нацелены на достижение целей в области предложения, таких как содействие развитию цифровых инфраструктур, улучшение доступа к широкополосной связи в районах с недостаточным уровнем и поддержка цифрового сектора. В последние годы большинство из них интегрировали в проекты конкретные цели в области спроса, такие как: содействие внедрению цифровых технологий предприятиями, особенно в секторе малых и средних предприятий (МСП) и фирмами в традиционных секторах экономики, расширение цифровых навыков и компетенций в обществе в целях содействия социальной интеграции и адаптации трудящихся к новым требованиям рынка труда. Новым направлением деятельности является разработка эффективных подходов к регулированию ицфровых сред. Например, стратегия «Цифровая Бельгия» (Digital Belgium) предусматривает формирование законодательства, благоприятствующего инновациям, с тем чтобы иннова- 
Примеры национальных цифровых стратегий

\begin{tabular}{|c|c|}
\hline Примеры стратегий & Главные цели \\
\hline $\begin{array}{l}\text { Техническое будущее } \\
\text { Австралии (Австралия) } \\
\text { Australia’s Tech Future }\end{array}$ & $\begin{array}{l}\text { Развитие цифровых навыков людей в целях обеспечения инклюзивного } \\
\text { общества } \\
\text { Улучшение предоставления государственных услуг в режиме онлайн } \\
\text { (электронное правительство) } \\
\text { Создание инфраструктуры и обеспечение безопасного доступа } \\
\text { к высококачественным данным } \\
\text { Укрепление кибербезопасности и пересмотр систем регулирования }\end{array}$ \\
\hline $\begin{array}{l}\text { Цифровая Бельгия } \\
\text { (Бельгия) } \\
\text { Digital Belgium }\end{array}$ & $\begin{array}{l}\text { Содействие развитию цифровой экономики } \\
\text { Инвестиции в цифровую инфраструктуру } \\
\text { Укрепление доверия и безопасности в сфере цифровых технологий } \\
\text { Содействие развитию цифровых навыков и рабочих мест } \\
\text { Развитие цифрового управления }\end{array}$ \\
\hline $\begin{array}{l}\text { Цифровизация } \\
\text { (Ирландия) } \\
\text { Doing more with digital }\end{array}$ & $\begin{array}{l}\text { Поддержка торговли онлайн и цифрового предпринимательства } \\
\text { Использование ИКТ в рамках всей системы образования } \\
\text { Увеличение числа пользователей Интернета } \\
\text { Улучшение предоставления государственных услуг в режиме онлайн } \\
\text { (электронное правительство) }\end{array}$ \\
\hline $\begin{array}{l}\text { ИКТ для всех - цифровая } \\
\text { программа для Швеции } \\
\text { (Швеция) ICT for } \\
\text { Everyone - A Digital } \\
\text { Agenda for Sweden }\end{array}$ & $\begin{array}{l}\text { Сделать Интернет и другие цифровые услуги простыми и безопасными } \\
\text { в использовании } \\
\text { Содействие развитию цифровых услуг, приносящих пользу } \\
\text { Развитие цифровой инфраструктуры } \\
\text { Укрепление роли ИКТ в развитии общества }\end{array}$ \\
\hline $\begin{array}{l}\text { Цифровая стратегия } 2017 \\
\text { (Великобритания) UK } \\
\text { Digital Strategy } 2017\end{array}$ & $\begin{array}{l}\text { Создание цифровой инфраструктуры мирового уровня } \\
\text { Предоставление каждому доступа к цифровым навыкам, необходимым для } \\
\text { содействия социальной интеграции } \\
\text { Стремление сделать Великобританию привлекательным местом для создания } \\
\text { и развития цифрового бизнеса } \\
\text { Предоставление помощи предприятиям во внедрении цифровых технологий } \\
\text { Укрепление кибербезопасности } \\
\text { Дальнейшее развитие электронного правительства } \\
\text { Открытие возможностей для использования данных и повышение доверия } \\
\text { общественности к их использованию }\end{array}$ \\
\hline
\end{tabular}

Источник. Авторская разработка по: OECD. 2019. The Digital Innovation Policy Landscape in 2019. Science, Technology and Industry Policy Papers. URL: https://www.oecd-ilibrary.org/science-and-technology/the-digitalinnovation-policy-landscape-in-2019_6171f649-en

ционные бизнес-модели при содействии цифровых технологий (например, в экономике совместного использования) могли функционировать в юридически стабильных рамках ${ }^{11}$.

Многие страны также недавно разработали отдельные стратегии для максимизации экономических и социальных выгод искусственного интеллекта (ИИ). На уровне ЕС приняты Программа ИИ для Европы (март 2018 г.) и связанный с ней Скоординированный план по ИИ (декабрь 2018 г.), которые направлены на содействие развитию и использованию ИИ в Европе ${ }^{12}$. Стратегии ИИ можно разделить на две группы: 1) страте-

\footnotetext{
11 URL: http://www.digitalbelgium.be/en

12 URL: https://ec.europa.eu/digital- single-market/en/ news/coordinated-plan-artificial-intelligence
}

гии, устанавливающие конкретный план действий и обеспечивающие прямое финансирование программ ИИ или непосредственно сопровождаемые бюджетными обязательствами (например, стратегии, принятые Канадой, Китаем, Францией, Германией, Южной Кореей и Великобританией $)^{13} ; 2$ ) «белые книги», или декларации, которые дают стратегические ориентиры для будущей политики (например, Япония, Мексика, Италия, Швеция, США) ${ }^{14}$.

${ }^{13}$ URL: https://www.de.digital/DIGITAL/Redaktion/EN/ Standardartikel/artificial-intelligence-strategy.html; URL:https:// www.cifar.ca/ai/pan-canadian-artificialintelligence-strategy

${ }^{14}$ URL: https://www.nedo.go.jp/content/100865202.pdf; URL: https://www.government.se/491fa7/contentassets/ fe2ba005fb49433587574c513a837fac/national- approach-toartificial-intelligence.pdf 
Анализ показывает ведущую роль правительств в решении проблем внедрения ИИ. США перед изданием Указа о сохранении американского лидерства в области искусственного интеллекта (февраль 2019 г.) в 2016 г. опубликовали Национальный стратегический план исследований и разработок в области искусственного интеллекта, установили ряд приоритетов для исследований, финансируемых из федерального бюджета, включая разработку методов сотрудничества людей и ИИ; выявили и устранили этические, правовые и социальные последствия ИИ и обеспечили охрану и безопасность систем ИИ. План сопровождался докладом «Подготовка к будущему искусственного интеллекта» ${ }^{15}$.

Общие цели большинства стратегий ИИ заключаются в следующем.

Усиление исследований в ИИ, например, путем создания новых исследовательских центров или выделения конкретных средств на программы исследований в области ИИ. В стратегиях ИИ Канады, Германии и Южной Кореи особое внимание уделяется действиям в этой области с целью стать международными лидерами в исследованиях ИИ.

Развитие способностей в сфере ИИ путем создания магистерских или докторских программ по ИИ, а также инициатив по привлечению, удержанию и обучению отечественных и международных исследователей ИИ. Франция и Канада создали программы ИИ для привлечения и удержания ведущих исследователей, а также для подготовки молодых исследователей. Секторальное соглашение по ИИ в Великобритании, финансируемое правительством и промышленностью, поддерживает программы стипендий докторам наук и магистрам по ИИ ${ }^{16}$, Япония планирует решить проблему нехватки ИИ путем создания новых программ и предоставления более высоких зарплат исследователям ${ }^{17}$.

Оказание поддержки предприятиям в разработке и внедрении прикладньх программ ИИ (разработка и внедрение ИИ деловыми

15 URL: https://obamawhitehouse.archives.gov/sites/ default/files/whitehouse_files/microsites/ostp/NSTC/natio nal_ai_rd_strategic_plan.pdf

${ }_{16}$ URL: https://www.gov.uk/government/publications/ artificial-intelligence-sector-deal/ai-sector-deal

${ }^{17}$ NEDO. 2017. Artificial Intelligence Technology Strategy. URL: https://www.nedo.go.jp/content/100865202.pdf кругами), например, путем предоставления конкретных финансовых средств для начинающих ИИ и МСП и содействия созданию кластеров ИИ. Великобритания принимает меры по распространению ИИ, в том числе инвестируя в высоконадежный бизнес ИИ через конкуренцию программ Фонда промышленных стратегий и программы венчурного капитала Британского делового банка ${ }^{18}$. Стратегия Японии в области технологии искусственного интеллекта устанавливает дорожную карту для поддержки распространения ИИ в секторах здравоохранения, социального обеспечения и мобильности ${ }^{19}$.

Разработка стандартов этического использования ИИ путем создания экспертных советов или комитетов по финансированию проектов для обеспечения этического и транспарентного развития ИИ. Шведский Национальный подход к ИИ подчеркивает важность соответствующих структур, чтобы гарантировать этическое, безопасное и устойчивое использование возможностей ИИ, особенно для алгоритмов ИИ, используемых государственным сектором ${ }^{20}$. Канадская стратегия предусматривает финансирование семинаров по вопросам ИИ и общества, в которых участвуют международные эксперты для изучения этических, а также более широких экономических, социальных и правовых результатов ИИ ${ }^{21}$.

В большинстве стран были созданы форумы или платформы для ИИ, с тем чтобы побудить различные заинтересованные стороны совместно разрабатывать дорожные карты и участвовать в стратегическом планировании в отношении ИИ. Форум искусственного интеллекта в Новой Зеландии был запущен в 2017 г. и объединяет технологических новаторов, связанных с ИИ, группы инвесторов, бизнес, предпринимателей, научные круги и правительство для выявления и поддержки возможностей ИИ в стране. Он занимается анализом исследований, которые позволяют получить

${ }^{18}$ URL: www.gov.uk/government/collections/industrialstrategy-challenge-fund-joint-research-and-innovation

${ }^{19}$ URL: https://www.nedo.go.jp/content/100865202.pdf

${ }^{20}$ URL: https://www.government.se/491fa7/content assets/fe2ba005fb49433587574c513a837fac/national-approachto-artificial-intelligence.pdf

${ }^{21}$ URL: www.cifar.ca/ai/pan-canadian-artificialintelligence-strategy 
информацию для обсуждения возможностей, проблем и потенциальных последствий ИИ в стране. Доклад «Искусственный интеллект: формирование будущего в Новой Зеландии» включает ряд политических рекомендаций ${ }^{22}$. Аналогичный пример - платформа Learning Systems в Германии ${ }^{23}$.

Растет также межстрановое сотрудничество в решении проблем ИИ на основе совместных действий и инвестиций. В апреле 2018 г. европейские страны-члены подписали Декларацию о сотрудничестве в области искусственного интеллекта. В этих рамках Франция и Германия уже разработали конкретные планы по созданию совместной сети исследований и разработок на основе существующих структур и конкретных навыков, которыми обладает каждая из этих двух стран. Ключевыми направлениями сотрудничества станут фундаментальные исследования, передача результатов исследований бизнесу, разработка регулятивных подходов и этических стандартов.

Все страны ОЭСР имеют одну или несколько стратегий в области науки, техники и инноваций (НТИ). Речь идет о поддержке науки в промышленности при внедрении технологий «Индустрия 4.0», а также умных сервисов, приложений больших данных (в частности, с акцентом на МСП), облачных вычислений, цифровых сетей, цифровой науки, цифрового образования и сред цифровой жизни. В пятом Базовом плане в области науки и техники в Японии подчеркивается важность создания «Общества 5.0», которое также определяется как «сверхумное общество» ${ }^{24}$. План предполагает развитие современных информационно-коммуникационных технологий (ИКТ) и Интернета вещей (IoT) в качестве одного из главных приоритетов политики в области науки и техники. Также рас-

\footnotetext{
22 URL: https://aiforum.org.nz/

23 Lernende Systeme. 2018. Germany's Platform for Artificial Intelligence. URL: https://www.plattform-lernendesysteme.de/home-en.html

24 План определяет «сверхумное общество» как общество, способное предоставлять необходимые товары и услуги людям, которые нуждаются в них в нужное время и в нужном количестве; общество, способное удовлетворять самые разнообразные социальные потребности; общество, в котором все люди могут легко получать качественные услуги, преодолевать различия относительно возраста, пола, региона и языка, а также иметь энергичную и комфортную жизнь.
}

сматриваются вопросы дальнейшего развития ИИ, минимизации рисков и установления пределов автоматизированного принятия решений ${ }^{25}$.

Несколько стран создали механизмь для обеспечения координащии цифровой трансформации в различных областях политики. Например, в Ю. Корее Президентский Комитет по четвертой промышленной революции, под председательством генерального директора IT Ventures, включает министров науки, промышленности, труда, представителей малых и средних предприятий и стартапов, а также ведущих специалистов из науки, промышленности и государственных учреждений. Стартовавшая в 2017 г. его основная миссия - разработка всеобъемлющего и ориентированного на человека национального плана по решению задач четвертой промышленной револющии содержит три стратегических приоритета: 1) создание инфраструктуры мирового уровня для интеллектуальных ИТ и фундаментальной науки; 2) содействие применению интеллектуальных ИТ во всех отраслях и государственных службах; 3) реформирование и адаптация услуг в области образования, занятости и социального обеспечения. Они нацелены на то, чтобы все граждане могли пользоваться преимуществами цифровой трансформации. Комитет также координирует планы действий и политику между министерствами, контролирует и оценивает осуществление соответствующих стратегий и проектов ${ }^{26}$.

В результате новых технологических прорывов и перспектив четвертой промышленной революции в странах возобновляется интерес к промышленной политике. В ряде государств в рамках стратегий в области НТИ или в качестве отдельных стратегий разработана промышленная политика ${ }^{27}$, обеспечивающая поддержку бизнес-инно-

\footnotetext{
25 URL: http://www.8.cao.go.jp/cstp/kihonkeikaku/ 5basicplan_en.pdf

26 URL: http://policy.creativekorea.or.kr/eng/

27 Промышленная политика определяется как «любой тип вмешательства или государственной политики с целью улучшить деловую среду или изменить структуру экономической деятельности отдельных секторов, технологий или задач, что, как ожидается, создаст лучшие перспективы для экономического роста или социального благосостояния, которые могли бы произойти в отсутствие такого вмешательства» (Warwick, 2013).
} 
ваций, причем иногда основное внимание уделяется конкретным технологическим областям или секторам. Промышленная политика в современных условиях направлена на обеспечение рамок, в которых национальные экономики развивают конкурентные преимущества в новых секторах экономики и фирмы могут осуществлять деятельность с высокой добавленной стоимостью в производственно-сбытовых цепочках. Развитие цифровых инноваций и внедрение новых цифровых технологий в промышленности (часто в традиционных секторах и МСП) находятся в центре этих инициатив. Для руководства процессом разработки и осуществления стратегий и конкретных действий в интересах «Индустрия 4.0» ряд правительств, часто совместно с бизнесом, создали новые платформы или форумы для обсуждения, в которых участвуют все ключевые заинтересованные стороны (представители промышленности, научных кругов, гражданского общества и правительства). Эти платформы способствуют обсуждению экономических и социальных последствий цифровой трансформации промышленности и направлены как на формирование общего видения, так и на выработку сбалансированных политических рекомендаций. Такими примерами являются: Plattform Industrie 4.0 в Германии, которая собирает представителей бизнеса, политиков и экспертов науки, ассоциаций и профсоюзов. Платформа призвана выявить все тенденции в развитии обрабатывающего сектора и объединить их для выработки общего понимания индустрии 4.0 и политических рекомендаций ${ }^{28}$; Plattform Industrie 4.0 (Австрия) объединяет учреждения науки, бизнеса, представителей региональной политики и национальной политики, ассоциаций, профсоюзов и НПО для организации процессов, стимулирующих цифровые преобразования, и обеспечивает получение нового знания и услуг для проекта «Индустрия 4.0». Данный проект осуществляется семью рабочими группами ${ }^{29}$.

${ }^{28}$ URL: http://www.de.digital/DIGITAL/Redaktion/EN/ Dossier/digital-hub-initiative.html

${ }^{29}$ URL: https://ec.europa.eu/growth/tools-databases/ dem/monitor/sites/default/files/DTM_PI4_AT_v2.pdf
Исследование показывает необходимость изменения модели инновационной политики. Современные вызовы привели к растущему интересу политиков к целенаправленным политическим подходам, чтобы инновации могли решить многие проблемы современности. Современные инновации являются неопределенными, кумулятивными и коллективными. Неопределенность означает, что агенты, занимающиеся инновациями, не могут заранее точно рассчитать возможности успеха или неудачи - результаты неизвестны, и поэтому им приходится принимать сбои и отклонения от запланированных маршрутов. Кумулятивность предполагает, что агенты должны быть терпеливыми и действовать стратегически, чтобы накапливать компетенции и способности с учетом долгосрочной перспективы, а государство - понимать и разделять риски. Коллективность означает, что всем агентам следует работать вместе и, таким образом, нести определенную степень риска; следовательно, они также имеют право делиться наградами/выгодами. Сложность современных инноваций и новые вызовы формируют трансформационную инновационную политику.

Трансформационная инновационная политика носит системный характер и выходит за рамки инструментов линейной модели и горизонтальных инструментов национальной инновационной системы. Формирование инновационных проектов, ориентированных на миссии, является важнейшим инструментом этой политики. Беларуси потребуется ряд финансовых и нефинансовых инструментов для содействия выполнению таких проектов во многих секторах, нацеленных на установление конкретных направлений развития экономики. Помимо расширения финансирования научных исследований со стороны государства, необходимо развивать новые отношения государства и бизнеса и укреплять доверие.

Эффективное согласование экономических интересов различных «макрогрупп» (Лученок, 2018) потребует изменения механизмов поддержки инноваций. Например, в распределении затрат на инновации. В 
2013 г. низкотехнологичный сектор экономики Беларуси требовал 13,6\% совокупных затрат на инновации, в 2018 г. - 11\%, а высокотехнологичный сектор экономики Беларуси за этот период лишь незначительно увеличил расходы с 5,5\% совокупных инновационных затрат до 7,9\%, т. е. сохранял существенно более низкие затраты. Государство, определяя стратегию развития сектора высоких технологий, призвано стимулировать интересы соответствующих экономических агентов, устраняя лоббирование со стороны макрогрупп традиционных секторов экономики, и организовать политический процесс так, чтобы мыслить масштабно и формулировать смелую политику, которая также создает доверие среди различных заинтересованных сторон: государственных, частных и академических. Развитие сектора высоких технологий в условиях цифровизации требует активизации процесса создания государственно-частных венчурных фондов, где участие государства должно быть достаточно весомым, что, в свою очередь, предполагает увеличение бюджетных расходов на науку.

Системная целенаправленная инновационная политика должна основываться на здравом и четком диагнозе и прогнозе (предвидении). Это требует не только выявления недостающих звеньев, сбоев и узких мест - слабостей или проблем национальной системы инноваций, но также и определения сильных сторон системы. Предвидение необходимо для изучения будущих возможностей, как сильные стороны могут помочь в преодолении слабых сторон. Этот диагноз следует использовать при разработке конкретных стратегий, новых институтов и новых связей в системе инноваций. Механизмы инновационных платформ и форумов, как показывает опыт, являются действенным инструментом согласования интересов различных участников инновационной деятельности. Для реализации проектов, ориентированных на миссии, важна возможность осуществлять политику, координируя усилия сети заинтересованных сторон через власть государства, устанавливая доверительные отношения и используя целевые инструменты политики.

\section{СПИСОК ЛИТЕРАТУРЫ (REFERENCES)}

Богдан Н. 2019. Инновационная политика. Минск: Четыре четверти. 308 c. [Bohdan N. 2019. Innovation policy. Minsk: Chetyre chetverti. 308 p. (In Russ.)]

Борнукова Е., Годес Н., Щерба Е. 2020. Доверие в экономике: что это, как работает и для чего нужно? Банковский вестник. № 3. С. 9599. [Bornukova E., Godes N., Shcherba E. 2020. Confidence in the economy: What is it, how it works and why we need it? Bankovskiy vestnik. No 3. PP. 95-99. (In Russ.)]

Гайдук К. 2020. Сектор госпредприятий: структурные вызовы. Банковский вестник. № 3. C. 26-30. [Haiduk K. 2020. Soe sector: Structural challenges. Bankovskiy vestnik. No 3. PP. 26-30. (In Russ.)]

Ковалев М.М., Головенчик Г.Г. 2018. Цифровая экономика - шанс для Беларуси. Минск: Издательский центр БГУ. 327 с. [Kovalev M.M., Golovenchik G.G. 2018. The digital economy is a chance for Belarus. Minsk: Izdatel'skiy tsentr BGU. (In Russ.)]

Крук Д. 2020. Экономический рост в Беларуси: идентификация барьеров и выбор приоритетов. Банковский вестник. № 3. C. 15-21. [Kruk D. 2020. Economic growth in Belarus: identification of barriers and choice of priorities. Bankovskiy vestnik. No 3. PP. 15-21. (In Russ.)]

Лузгина А. 2020. Цифровая трансформация национальной экономики: вызовы и перспективы развития. Банковский вестник. № 3. С. 100-105. [Luzgina A. 2020. Digital transformation of the national economy: Challenges and development prospects. Bankovskiy vestnik. No 3. PP. 100-105. (In Russ.)]

Лученок А. 2018. Институты правят экономикой. Минск: Беларуская навука. 278 с. [Luchenok A. 2018. Institutions rule the economy. Minsk: Belaruskaya navuka. 278 p. (In Russ.)]

Cohen W.M., Levinthal D.A. 1989. Innovation and learning: the two faces of R\&D. Economic Journal. Vol. 99. PP. 569-596.

Dutrénit G., Sutz J. (Eds.). 2014. National Innovation Systems. Social Inclusion and Development. The Latin American Experience. Cheltenham UK: Edward Elgar Publishing.

Etzkowitz H., Leydesdorff L. (Eds.) 1997. Universities and the global knowledge economy: A triple helix of university-industry-government relations. London: Cassell Academic.

Foray D., Mowery D.C., Nelson R.R. 2012. Public R\&D and social challenges: What lessons from mission R\&D programs. Research Policy. Vol. 41. Iss. 10. PP. 1697-1702.

Freeman C. 1988. Japan: a new national system of innovation. Technical Change and Economic Theory. London: Pinter Publishers. PP. 330-348. 
Kaplinsky R. 2011. Schumacher meets Schumpeter: Appropriate technology below the radar. Research Policy. Vol. 40. Iss. 2. PP. 193-203.

Kline S.J., Rosenberg N. 1986. An overview of innovation. The Positive Sum Strategy: Harnessing Technology for Economic Growth. Washington DC: Academy Press. PP. 275-307.

Kuznets S. 1973. Modern economic growth: findings and reflections. American Economic Review. Vol. 63. No 3. PP. 247-258.

Lundvall B.-A. (Ed.) 1992. National Systems of Innovation: Towards a Theory of Innovation and Interactive Learning. London: Pinter Publishers.

Mazzucato M. 2017. Mission-oriented Innovation Policy: Challenges and Opportunities. UCL Institute for Innovation and Public Purpose. Working Paper (20171). URL: https://www.ucl.ac.uk/bartlett/publicpurpose/sites/public-purpose/files/moipchallenges-and-opportunities-working-paper-2017-1.pdf

Mazzucato M. 2018. Mission-Oriented Research $\mathcal{E}$ Innovation in the European Union. A problem-solving approach to fuel innovation-led growth. Luxembourg: Publications Office of the European Union. URL: https:/ /ec.europa.eu/jrc/communities/sites/jrccties/files/ mazzucato_report_2018_0.pdf
Meadows D.H., Meadows D.L., Randers J., Behrens W.W. 1972. The Limits to Growth. A Report for the Club of Rome's Project on the Predicament of Mankind. New York: Univers Books.

Schot J., Steinmueller W.E. 2018. Three frames for innovation policy: R\&D, systems of innovation and transformative change. Research Policy, Elsevier. Vol. 47. Iss. 9. PP. 1554-1567.

Soete L. 2013. From emerging to submerging economies: new policy challenges for research and innovation. Science, Technology and Innovation Policy Review. Vol. 4. No 1. PP. 1-13.

Steffen W., Richardsonand K., Rockström J., Cornell S.E. 2015. Planetary boundaries: Guiding human development on a changing planet. Science. Vol. 347. Iss. 6223. PP. 736-746.

von Hippel E. 1976. The dominant role of users in the scientific instrument innovation process. Research Policy. Vol. 5. Iss. 3. PP. 212-239.

von Hippel E. 1988. The Sources of Innovation. New York: Oxford University Press.

Warwick K. 2013. «Beyond Industrial Policy: Emerging Issues and New Trends». OECD Science, Technology and Industry Policy Papers. No 2. URL: https://doi.org/10.1787/5k4869clw0xp-en

In citation: Belorusskiy Economicheskiy zhurnal. 2020. No 3. PP. 4-20.

Belarusian Economic Journal. 2020. No 3. PP. 4-20.

\title{
TECHNOLOGY AND INNOVATION POLICY: WORLD PRACTICE AND CHALLENGES FOR THE REPUBLIC OF BELARUS
}

\author{
Nina Bohdan ${ }^{1}$
}

Authors affiliation: ${ }^{1}$ Belarusian State Economic University (Minsk, Belarus).

Corresponding author: Nina Bohdan (bohdannina@gmail.com).

ABSTRACT. The article considers theoretical aspects of creating a new model of innovation policy known as a transformational one. It aims at harmonization of social and environmental concerns with innovation objectives. Upon analyzing foreign practices two main tendencies in current transformational innovation policy are revealed. And those are developing mission-focused innovative projects and fostering cooperation between authorities and business in the age of digital transformation. In this context directions of improvement were suggested for further enhancements to the innovation policy of the Republic of Belarus.

KEYWORDS: innovation policy, innovative projects, transformation, mission, digital transformation.

JEL-code: O30, O38.

DOI: $10.46782 / 1818-4510-2020-3-4-20$

Received 24.06.2020 